\title{
Geographical Origin Identification of Tequila Based on Multielement and Stable Isotopes
}

\author{
Jian Zhang, Yiqian Ma $\mathbb{D}^{D}$, Feilong Shao, Yuanyu Lu, Libo Zhu, and Xiansong Xu \\ Guizhou Institution of Products Quality Inspection \& Testing, Guiyang 550016, China \\ Correspondence should be addressed to Yiqian Ma; 326668213@qq.com
}

Received 8 December 2020; Revised 12 May 2021; Accepted 8 June 2021; Published 23 June 2021

Academic Editor: Daniel Cozzolino

Copyright (c) 2021 Jian Zhang et al. This is an open access article distributed under the Creative Commons Attribution License, which permits unrestricted use, distribution, and reproduction in any medium, provided the original work is properly cited.

\begin{abstract}
To explore the regional characteristics of multielement and stable isotopes in tequila and the viability of tracing the geographical origin, both inductively coupled plasma mass spectrometry (ICP-MS) and stable isotope ratio mass spectrometry (IRMS) were applied in this study to determine the multielement content and stable isotope ratios of tequila. Then, principal component analysis (PCA) and partial least squares discriminant analysis (PLS-DA) as chemometrics were conducted in combination to establish a model for determining the geographical origin of Mexican tequila. According to the analytical results, the content of 22 elements varied, as did the ranges of stable isotope $\delta^{13} \mathrm{C}$ and $\delta^{18} \mathrm{O}$ values for the tequila obtained from the 4 producing areas. Besides, there were regional characteristics shown to some extent. PCA and PLS-DA methods can be adopted to identify the geographical origin of tequila in Mexico. According to the discriminant verification of 16 samples, the accuracy of prediction reached $93.75 \%$. It has been demonstrated that it is possible to distinguish tequila of different geographical origins in Mexico by combining the determination of the multielement content and stable isotope ratios with chemometric analysis, which lays a foundation for tracing the geographical origin of tequila.
\end{abstract}

\section{Introduction}

Tequila refers to a distilled alcoholic product made from blue agave grown across the 4 legal states of Mexico including Jalisco, Guanajuato, Michoacan, and Tamaulipas. In 2014, the Chinese market was opened up to Mexican tequila, which made the country of origin (geographical indication) trademark of Mexican tequila recognized. As the imports and consumption of tequila by Chinese consumers are increasing on a continued basis in China, there has been a phenomenon arising where illegal merchants bring fake or shoddy products on the market for sale. Consequently, the quality of tequila in the domestic market is made uneven, with a disconnect between quality and pricing emerging. Therefore, it is imperative to develop new technologies that are effective, fast, and accurate in identifying the geographical origin and quality of tequila.

At present, such solutions as mineral element fingerprint method [1-4], aroma fingerprint method [5], and stable isotope mass spectrometry (IRMS) technology [6-8] have been commonly applied for food production. Among them, the stable isotope ratio method performs well in indicating regional and climatic characteristics. It is widely used to trace food geographical origin, for example, wine [9], beef $[10]$, and tea $[11,12]$. Besides, it can be applied for authentication, such as the brewing of soy sauce [13] and honey [14-16]. The content of mineral elements in tequila is largely determined by the environmental conditions of its growth, such as soil, water, and climate. Since it is difficult to metabolize or change them during the brewing and aging process, they can be taken as an important marker used to identify the geographical origin of tequila. It is possible to use the carbon 13 isotopic ratio $\left(\delta^{13} \mathrm{C}_{\mathrm{VPDB}}\right)$, oxygen 18 isotopic ratio $\left(\delta^{18} \mathrm{O}_{\mathrm{VSMOW}}\right)$, and the element content as complementary parameters of authenticity to identify tequila and tequila $100 \%$ agave (silver class) $[17,18]$. Using the 49 mineral elements combined with the stable isotope ratios of C, N, O, S, and Sr, Bontempo et al. [19] identified the geographical origin of 10 cheese samples obtained from the Alps; the correct classification rate of the samples reached up 
to $94 \%$. Shao Shengzhi et al. [20] combined principal component analysis (PCA) and linear discriminant analysis (LDA) as chemometrics. They used the contents of 23 mineral elements and the stable isotope ratios of $\mathrm{C}, \mathrm{N}, \mathrm{O}$, and $\mathrm{H}$ to conduct discriminant verification on 23 rice samples obtained from Heilongjiang, Jiangsu, and Liaoning provinces. Ultimately, the accuracy reached as high as $91 \%$. Combined with the stoichiometric PCA-LDA, Yuan Yuwei et al. [11] used the content of 27 mineral elements and the stable isotope ratios of $\mathrm{C}, \mathrm{N}, \mathrm{O}$, and $\mathrm{H}$ to identify the tea obtained from Fujian, Shandong, and Zhejiang, with the accuracy rate reaching $99 \%$. It can be judged from above that the use of stable isotopes and mineral elements in combination with stoichiometry can produce a better outcome in tracing the geographical origin of tea.

Being one of the multivariate analysis techniques, PCA (principal component analysis) is frequently conducted as a dimension-reduction tool to reduce a large set of variables to a small set that remains capable of containing most of the information in the large set. Considering this, PCA was employed for the transformation of largely correlated variables of this work into smaller uncorrected variables [21]. PLS-DA (partial least squares discriminant analysis) is a linear classification method that combines the properties shown by partial least square regression with the discrimination power of a classification technique [22].

In this study, mineral elements and stable isotope ratios were combined with principal component analysis (PCA) and partial least squares discriminant analysis (PLS-DA) as chemometrics. On this basis, a solution was developed to trace and identify the geographical origin of tequila obtained from the 4 legal regions of Mexico, which provides technical support for ensuring the authenticity of the Mexican tequila imported to China.

\section{Materials and Methods}

2.1. Instruments and Reagents. DRC-e Inductively Coupled Plasma Mass Spectrometer (ICP-MS) is from PerkinElmer, USA. DELTA V Plus Isotope Mass Spectrometer (IRMS) is from Thermo Fisher Company, USA, equipped with Trace GC gas chromatograph. The instrument control software used in this study is ISODATE 3.0. GasBench II preprocessing devices are GC PAL autosampler, PoraPlot $Q$ column $(25 \mathrm{~m}, 0.32 \mathrm{~mm})$, screw cap vial, injection needle, and blowing needle. Gas chromatography column is RTX-WAX $(30 \mathrm{~m} \times 0.25 \mathrm{~mm} \times$ $0.25 \mu \mathrm{m})$. Carbon isotope standard material in carbon black is $\delta^{13} C_{\mathrm{VPDB}}=(-36.91 \pm 0.10) \%$. Hydrogen and oxygen isotope water standard material GBW04458 is $\delta^{18} O_{\mathrm{VSMOW}}=(-0.15$ $\pm 0.07) \%$ and GBW04459 is $\delta^{18} O_{\text {VSMOW }}=(-8.61 \pm 0.08) \%$, with high purity helium (99.999\%); standard reference gas $\mathrm{CO}_{2}$ was purchased from China Shengying Company. Multielement standard solution is from PerkinElmer, USA. Milli-Q Gradient pure water treatment system is from Millipore, France.

2.2. Materials. The importers were entrusted with the purchase of totally 60 original bottles of tequila as obtained from 4 legal production areas in Mexico, with 13 bottles from Jalisco, 15 bottles from Guanajuato, 15 bottles from Michoacan, and 17 bottles from Tamaulipas. Among them, 44 tequila wines were used for constructing the geographical origin traceability model, and the remaining 16 were used to carry out model verification.

2.3. Sample Preparation. Firstly, $25 \mathrm{~mL}$ of tequila sample was placed into a water bath at $100^{\circ} \mathrm{C}$ for the complete removal of alcohol through evaporation. Secondly, it was being diluted to $25 \mathrm{~mL}$ again by $1 \%$ nitric acid solution for later multielement analysis [23]. Thirdly, $20 \mu \mathrm{L}$ of tequila sample was placed into the gas chromatography bottle and then was added with $1 \mathrm{~mL}$ of chromatographic pure acetone to analyze the stable carbon isotope ratio of ethanol. Besides, $0.5 \mathrm{~mL}$ of tequila sample was placed into a screw cap sample bottle, which was filled with a mixture of $0.3 \% \mathrm{CO}_{2}$ and $\mathrm{He}$ for $300 \mathrm{~s}$ to remove the air present in the bottle. Then, it was equilibrated for 18-24 hours. Finally, the gaseous $\mathrm{CO}_{2}$ and oxygen present in the water were exchanged for an isotope, to facilitate the analysis of the stable oxygen isotope in the water.

\subsection{Instrument Conditions}

2.4.1. ICP-MS Measurement Conditions [23]. RF power is $1100 \mathrm{~W}$. Nebulizer flow rate is $0.88 \mathrm{~L} / \mathrm{min}$. Cooling air flow rate is $16 \mathrm{~L} / \mathrm{min}$. Auxiliary gas flow rate is $1.2 \mathrm{~L} / \mathrm{min}$. Ion lens voltage is $6 \mathrm{~V}$. As for the determination of arsenic element, a dynamic reaction cell mode was adopted. Parameters are cell gas $\mathrm{A}: 0.3$; $\mathrm{RPq}: 0.5$.

\subsubsection{IRMS Measurement Conditions}

(1) Stable Carbon Isotope Determination Conditions. Column is RTX-WAX $(30 \mathrm{~m} \times 0.25 \mathrm{~mm}, 0.25 \mu \mathrm{m})$. Injection volume is $1 \mu \mathrm{L}$. Carrier gas is high purity. Flow rate is $1.2 \mathrm{~mL} /$ min. Split ratio is $30: 1$. Inlet temperature is $200^{\circ} \mathrm{C}$. The heating program is detailed as follows. The initial temperature is $40^{\circ} \mathrm{C}$, which is kept for $5 \mathrm{~min}$. Then, it raised to $80^{\circ} \mathrm{C}$ at a rate of $10^{\circ} \mathrm{C} / \mathrm{min}$, which is kept for $1 \mathrm{~min}$. Finally, it raised to $200^{\circ} \mathrm{C}$ at a rate of $25^{\circ} \mathrm{C} / \mathrm{min}$, which was kept for $15 \mathrm{~min}$. Combustion tube temperature is $1000^{\circ} \mathrm{C}$. Ion source voltage is $2.97 \mathrm{KV}$. Vacuum degree is $1.6 \times 10^{-6} \mathrm{mBar}$. Bombardment voltage is $123.8 \mathrm{eV}$.

(2) Stable Oxygen Isotope Measurement Conditions. Carrier gas is helium. Carrier gas pressure is 0.9 bar. Reference gas is $\mathrm{CO}_{2}$. Reference gas pressure is 1.3 bar. Column temperature is $65^{\circ} \mathrm{C}$. There is a Polar Plot $Q$ column. Ion source voltage is $2.97 \mathrm{KV}$. Vacuum degree is $1.6 \times 10^{-6} \mathrm{mBar}$. Bombardment voltage is $123.8 \mathrm{eV}$.

2.5. Data Processing. Thermo Electron Isodat version 3.0 software was applied to perform isotope ratio calculation and data acquisition. Principal component analysis (PCA) and partial least squares discriminant analysis (PLS-DA) were conducted using $R$ language. Origin 9.0 (Origin lab, USA) was adopted to carry out data mapping. 


\section{Results and Discussion}

3.1. Precision and Accuracy. In our previous study [23], an investigation was conducted into the precision and accuracy of ICP-MS. On this basis, a total of 22 elements in tequila were determined through standard recovery experiments. For each element to be tested, the standard addition recovery rate falls within the range of $90 \sim 110 \%$, which is consistent with the results of the 8 elements found in the previous study of food carried out by this group [24]. It was finally demonstrated that ICP-MS can meet the detection requirements of various elements.

According to the quality control requirements specified for international testing methods [25], the measurement deviation for the $\delta^{13} \mathrm{C}$ value of quality control standards and samples is required not to exceed $0.5 \%$ and $0.3 \%$, respectively. The carbon isotope and oxygen isotope calibration of the reference gas $\mathrm{CO}_{2}$ was conducted using the carbon black standard material as well as the hydrogen and oxygen isotope water standard material. As shown in Table 1, the standard deviation shown by the $\delta^{13} \mathrm{C}$ value of the reference gas $\mathrm{CO}_{2}$ is $0.016 \%$, and the standard deviation of the oxygen isotope ratio $\delta^{18} \mathrm{O}$ is less than $0.06 \%$, which meets the testing requirements of the experimental requirements.

The same sample was used to repeatedly examine the accuracy of the experimental method. According to the abovementioned experimental conditions and procedures, the carbon isotope ratio of ethanol in the same sample was measured 8 times by GC-IRMS, while the oxygen isotope ratio of water in the same sample was measured 8 times by GasBench II-IRMS. Then, the standard deviation was calculated, and the results were obtained, as listed in Table 2. The standard deviations shown by the $\delta^{13} \mathrm{C}$ value of ethanol and the $\delta^{18} \mathrm{O}$ value of water in tequila are $0.12 \%$ and $0.03 \%$, respectively, which meets the accuracy requirements of the experiment.

3.2. Geographical Origin Traceability Analysis. In order to assess the multielement content in tequila, carbon and oxygen stable isotope ratio analysis was conducted of their effectiveness in tracing the geographical origin of tequila obtained from 4 legal production areas in Mexico, including Jalisco, Guanajuato, Michoacan, and Tamaulipas. This method was used to determine the multielement content in tequila, the carbon isotope ratio of ethanol, and the oxygen isotope ratio of water. As indicated by the analytical results, there are variations in the multielement content of tequila obtained from different geographical origins as shown in Table 3 [23]. Besides the carbon and oxygen isotope ratio shown Table 4, the $\delta^{13} \mathrm{C}$ experimental data are in a range of $-14.29 \%$ and $-12.60 \%$. Similar results have been reported for a range of $-12.1 \%$ to $-13.2 \%$ [26] and a range of $-11.0 \%$ to $-14.0 \%$ [17], which suggests that the multielement content as well as carbon and oxygen isotope ratios of tequila varies between different geographical origins. Therefore, these can be used to assist geographical origin traceability analysis.

3.3. Model Building. There are significant differences exhibited by the results obtained from the single-factor analysis of variance for the stable carbon isotope $\delta^{13} \mathrm{C}$ and oxygen isotope $\delta^{18} \mathrm{O}$ in tequila obtained from the four tequila-producing areas, the results of principal component analysis for the content of 22 metal elements, and the results of six principal components' analysis for a metallic element. Table 5 indicates the cumulative contribution rate of the principal component analysis of 22 variances, respectively. Normally, parameters need to exceed $75 \%$, and the characteristic root value is greater than or equal to 1 of the principal component, which will be deemed sufficient [20]. The biggest contributor is made up of 6 elements $(\mathrm{Sr}, \mathrm{Pb}, \mathrm{Se}$, $\mathrm{V}, \mathrm{Ca}$, and $\mathrm{Fe}$ ) with $91.59 \%$ contributions in this PCA model. Therefore, the geographical origin traceability model can be constructed to identify the exact geographical origin. Partial least squares discriminant analysis (PLS-DA) was performed on 44 samples obtained from 4 production areas, including Guanajuato, Jalisco, Michoacan, and Tamaulipas. The results are shown in Figures 1 and 2, respectively.

As shown in Figures 1 and 2, the tequila in the four regions can be effectively distinguished by stable carbon, oxygen isotope, and multielement analysis. Tamaulipas is concentrated in the area formed by the negative semiaxis of $\mathrm{PC} 1$ and PC2. In comparison the remaining three regions (Guanajuato, Jalisco, and Michoacan) are concentrated in the area of the positive semiaxis of PC1. These can be differentiated more effectively.

3.4. Model Validation. According to Table 6, one sample obtained from Guanajuato is misjudged as Tamaulipas, with the prediction accuracy reaching $75 \%$. The other three production areas are all distinguished correctly, with the prediction accuracy reaching $100 \%$. Therefore, the model is verified as reliable, with an overall prediction accuracy of $93.75 \%$. Despite this, an effort will be continued in the future to increase the sample size and expand the existing database. Meanwhile, an attempt will be made to achieve technical cooperation with Mexican tequila related laboratories for acquiring more technical information about local tequila and tequila, such as local climatic data and local oxygen isotope data in surface water. In this way, a data base can be constructed that is more reliable, informative, and closer to the real-world local conditions. 
TABle 1: Precision of $\delta^{13} \mathrm{C}$ values and $\delta^{18} \mathrm{O}$ values of the standard.

\begin{tabular}{lccc}
\hline Number & Carbon black standard $\delta^{13} \mathrm{C}(\%)$ & GBW04458 $\delta^{18} \mathrm{O}(\%)$ & GBW04459 $\delta^{18} \mathrm{O}(\%)$ \\
\hline 1 & -21.73 & -30.20 & -30.34 \\
2 & -21.71 & -30.09 & -30.38 \\
3 & -21.74 & -30.15 & -30.33 \\
4 & -21.70 & -30.17 & -30.30 \\
5 & -21.73 & -30.12 & -30.35 \\
6 & -21.75 & -30.13 & -30.37 \\
7 & -21.73 & -30.23 & -30.37 \\
8 & -21.74 & -30.10 & -30.41 \\
Means & -21.73 & -30.15 & -30.36 \\
SD & 0.016 & 0.05 & 0.03 \\
\hline
\end{tabular}

*The data in the table has been automatically calibrated by the instrument to the value of the international standard V-PDB and V-SMOW.

TABle 2: Accuracy of $\delta^{13} \mathrm{C}$ values and $\delta^{18} \mathrm{O}$ values of tequila by isotope ratio mass spectrometry.

\begin{tabular}{lcc}
\hline Number & $\delta^{13} \mathrm{C}(\%)$ & $\delta^{18} \mathrm{O}(\%)$ \\
\hline 1 & -12.42 & -13.21 \\
2 & -12.47 & -13.26 \\
3 & -12.31 & -13.23 \\
4 & -12.54 & -13.29 \\
5 & -12.57 & -13.24 \\
6 & -12.36 & -13.24 \\
7 & -12.65 & -13.27 \\
8 & -12.59 & -13.22 \\
Mean & -12.49 & -13.24 \\
SD & 0.12 & 0.03 \\
\hline$*$
\end{tabular}

${ }^{*}$ The data shown in the table has been automatically calibrated by the instrument to the value of the international standard V-PDB and V-SMOW.

TABLE 3: Element contents of tequila by ICP-MS.

\begin{tabular}{|c|c|c|c|c|c|c|c|c|c|c|c|}
\hline \multirow{2}{*}{ Element } & \multicolumn{11}{|c|}{ Sample } \\
\hline & 1 & 2 & 3 & 4 & 5 & 6 & 7 & 8 & 9 & 10 & 11 \\
\hline $\mathrm{Li}$ & 0.702 & 1.766 & 1.954 & 1.449 & 3.164 & 2.766 & 3.074 & 0.271 & 0.421 & 0.523 & 0.572 \\
\hline $\mathrm{Na}$ & 701.451 & 2473.342 & 2572.231 & 2888.809 & 4844.875 & 4723.982 & 4928.522 & 3314.101 & 1451.076 & 2117.161 & 2172.331 \\
\hline $\mathrm{Mg}$ & 39.605 & 126.945 & 28.229 & 96.348 & 58.168 & 25.749 & 67.137 & 37.358 & 142.561 & 108.01 & 49.467 \\
\hline $\mathrm{Al}^{\circ}$ & 15.006 & 2.313 & 0.892 & 9.422 & 7.783 & 13.326 & 16.818 & 34.99 & 7.617 & 40.572 & 17.984 \\
\hline $\mathrm{K}$ & 125.784 & 221.634 & 1244.744 & 583.98 & 363.914 & 368.183 & 322.903 & 672.762 & 144.387 & 155.049 & 267.881 \\
\hline $\mathrm{Ca}$ & 106.771 & 276.097 & 177.873 & 216.988 & 195.954 & 74.38 & 193.409 & 190.63 & 475.065 & 398.741 & 242.484 \\
\hline $\mathrm{V}$ & 0.122 & 0.161 & 0.08 & 0.116 & 0.056 & 0.062 & 0.092 & 0.53 & 0.195 & 0.975 & 0.214 \\
\hline $\mathrm{Cr}$ & 0.602 & 1.579 & 0.887 & 1.118 & 11.733 & 17.91 & 6.579 & 1.002 & 4.724 & 16.338 & 12.874 \\
\hline Mn & 1.671 & 4.52 & 0.723 & 1.802 & 1.925 & 0.842 & 2.68 & 3.666 & 3.318 & 7.267 & 2.715 \\
\hline $\mathrm{Fe}$ & 0.681 & 5.731 & 1.37 & 9.791 & 3.908 & 4.423 & 5.644 & 10.708 & 6.678 & 12.129 & 13.901 \\
\hline Co & 0.069 & 0.086 & 0.048 & 0.097 & 0.084 & 0.081 & 0.126 & 0.143 & 0.095 & 0.519 & 0.464 \\
\hline $\mathrm{Ni}$ & 0.344 & 0.253 & 0.149 & 0.577 & 1.731 & 0.256 & 0.466 & 0.446 & 0.432 & 1.631 & 0.936 \\
\hline $\mathrm{Cu}$ & 20.022 & 420.761 & 4.858 & 978.182 & 4.728 & 4.557 & 4.191 & 328.793 & 0.759 & 1.438 & 1.113 \\
\hline $\mathrm{Zn}$ & 1.795 & 7.424 & 0.202 & 26.846 & 2.22 & 0.937 & 2.007 & 2.219 & 2.139 & 3.236 & 3.143 \\
\hline As & 1.246 & 0.853 & 0.487 & 0.483 & 0.392 & 0.413 & 0.291 & 0.219 & 0.81 & 0.973 & 0.948 \\
\hline $\mathrm{Se}$ & 0.207 & 0.145 & 0.145 & 0.104 & 0.217 & 0.163 & 0.098 & 0 & 0.582 & 0.684 & 0.559 \\
\hline $\mathrm{Ag}$ & 0.07 & 0.033 & 0.014 & 0.011 & 0.011 & 0.016 & 0.014 & 0.013 & 0.004 & 0 & 0 \\
\hline $\mathrm{Cd}$ & 0.016 & 0.025 & 0 & 0.034 & 0 & 0.012 & 0 & 0.007 & 0.007 & 0 & 0.009 \\
\hline $\mathrm{Ba}$ & 0 & 0.849 & 0 & 1.608 & 2.226 & 0 & 0.526 & 2.109 & 2.939 & 0 & 0 \\
\hline $\mathrm{Pb}$ & 0.031 & 0.202 & 0.277 & 0.875 & 0.227 & 0.108 & 0.288 & 0.02 & 0.286 & 4.242 & 4.431 \\
\hline $\mathrm{Bi}$ & 0.402 & 0.105 & 0.022 & 0.008 & 0 & 0 & 0 & 0 & 0 & 0 & 0 \\
\hline $\mathrm{Sr}$ & 0.389 & 2.23 & 0.261 & 1.228 & 1.076 & 0.375 & 1.55 & 1.518 & 6.486 & 7.18 & 3.293 \\
\hline
\end{tabular}


TABLE 4: $\delta^{13} \mathrm{C}$ values and $\delta^{18} \mathrm{O}$ values of stable isotope ratio in tequila.

\begin{tabular}{lcc}
\hline Geographical origin & Ethanol $\delta^{13} \mathrm{C}$ value & Water $\delta^{18} \mathrm{O}$ value \\
\hline Guanajuato & -13.67 & -13.24 \\
Guanajuato & -13.56 & -13.11 \\
Guanajuato & -13.62 & -13.29 \\
Guanajuato & -13.5 & -13.38 \\
Guanajuato & -13.71 & -13.44 \\
Michoacan & -14.04 & -9.76 \\
Michoacan & -14.13 & -9.62 \\
Michoacan & -14.18 & -9.8 \\
Michoacan & -14.3 & -9.72 \\
Michoacan & -12.74 & -12.11 \\
Michoacan & -12.6 & -11.97 \\
Jalisco & -14.12 & -9.32 \\
Jalisco & -14.29 & -9.41 \\
Jalisco & -14.18 & -9.36 \\
Jalisco & -14.09 & -9.33 \\
Jalisco & -13.86 & -9.12 \\
Tamaulipas & -14.09 & -9.26 \\
Tamaulipas & -14.16 & -9.48 \\
Tamaulipas & -13.75 & -13.14 \\
Tamaulipas & -13.52 & -13.02 \\
Tamaulipas & -13.83 & -13.13 \\
Tamaulipas & -13.68 & -13.22 \\
\hline
\end{tabular}

TABle 5: Component score coefficient matrix in tequila.

\begin{tabular}{|c|c|c|c|c|c|c|}
\hline \multirow{2}{*}{ Elements } & \multicolumn{6}{|c|}{ Component } \\
\hline & 1 & 2 & 3 & 4 & 5 & 6 \\
\hline $\mathrm{Li}$ & -0.072 & -0.137 & -0.023 & -0.082 & 0.314 & 0.051 \\
\hline $\mathrm{Na}$ & -0.042 & -0.209 & 0.028 & 0.030 & 0.186 & 0.211 \\
\hline $\mathrm{Mg}$ & 0.065 & 0.081 & 0.166 & -0.213 & 0.144 & 0.036 \\
\hline $\mathrm{Al}$ & 0.080 & -0.038 & -0.045 & 0.221 & -0.172 & 0.383 \\
\hline K & -0.060 & -0.080 & 0.051 & 0.109 & -0.350 & -0.286 \\
\hline $\mathrm{Ca}$ & 0.096 & 0.028 & 0.116 & -0.228 & -0.063 & -0.054 \\
\hline V & 0.101 & -0.005 & -0.002 & 0.131 & -0.191 & 0.257 \\
\hline $\mathrm{Cr}$ & 0.058 & -0.141 & -0.119 & 0.013 & 0.290 & -0.012 \\
\hline $\mathrm{Mn}$ & 0.105 & 0.025 & 0.037 & 0.002 & -0.037 & 0.278 \\
\hline $\mathrm{Fe}$ & 0.093 & -0.043 & 0.106 & 0.207 & -0.008 & -0.066 \\
\hline Co & 0.111 & -0.030 & -0.065 & 0.158 & 0.041 & -0.128 \\
\hline $\mathrm{Ni}$ & 0.074 & -0.083 & -0.022 & 0.013 & 0.232 & 0.189 \\
\hline $\mathrm{Cu}$ & -0.024 & 0.071 & 0.242 & 0.223 & 0.090 & 0.003 \\
\hline $\mathrm{Zn}$ & -0.009 & 0.068 & 0.224 & 0.204 & 0.224 & -0.118 \\
\hline As & 0.056 & 0.185 & -0.125 & -0.042 & 0.109 & -0.150 \\
\hline $\mathrm{Se}$ & 0.108 & 0.021 & -0.063 & -0.133 & 0.072 & -0.228 \\
\hline $\mathrm{Ag}$ & -0.050 & 0.167 & -0.140 & 0.054 & 0.062 & 0.256 \\
\hline $\mathrm{Cd}$ & -0.027 & 0.170 & 0.092 & 0.144 & 0.237 & 0.029 \\
\hline $\mathrm{Ba}$ & 0.000 & -0.012 & 0.212 & -0.214 & -0.075 & 0.249 \\
\hline $\mathrm{Pb}$ & 0.103 & -0.018 & -0.060 & 0.169 & 0.091 & -0.271 \\
\hline $\mathrm{Bi}$ & -0.033 & 0.200 & -0.141 & 0.018 & 0.030 & 0.169 \\
\hline $\mathrm{Sr}$ & 0.115 & 0.019 & 0.045 & -0.158 & -0.031 & -0.013 \\
\hline
\end{tabular}

${ }^{*}$ Extraction method: principal component analysis. 


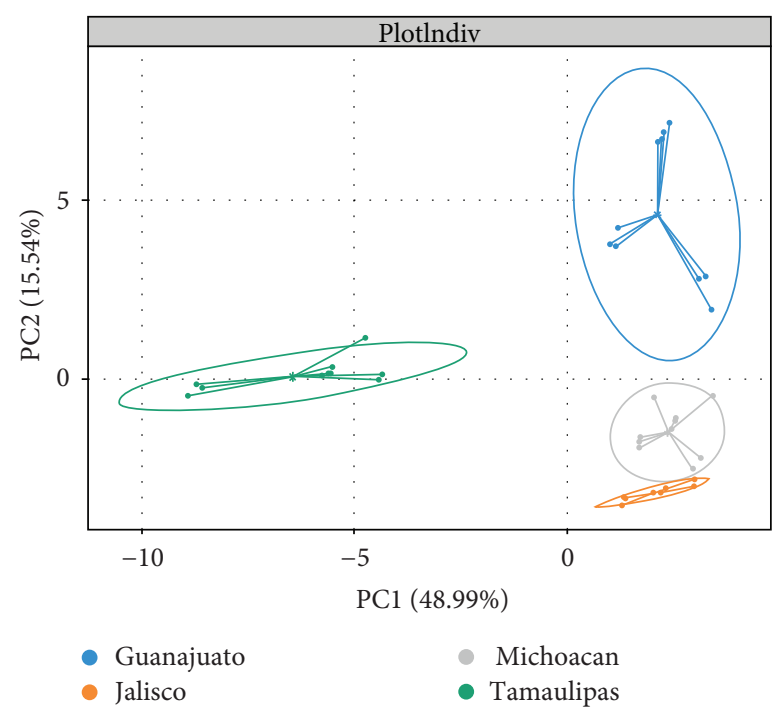

Figure 1: The two-dimensional figure of the PLS-DA model of identification of Mexican tequila.

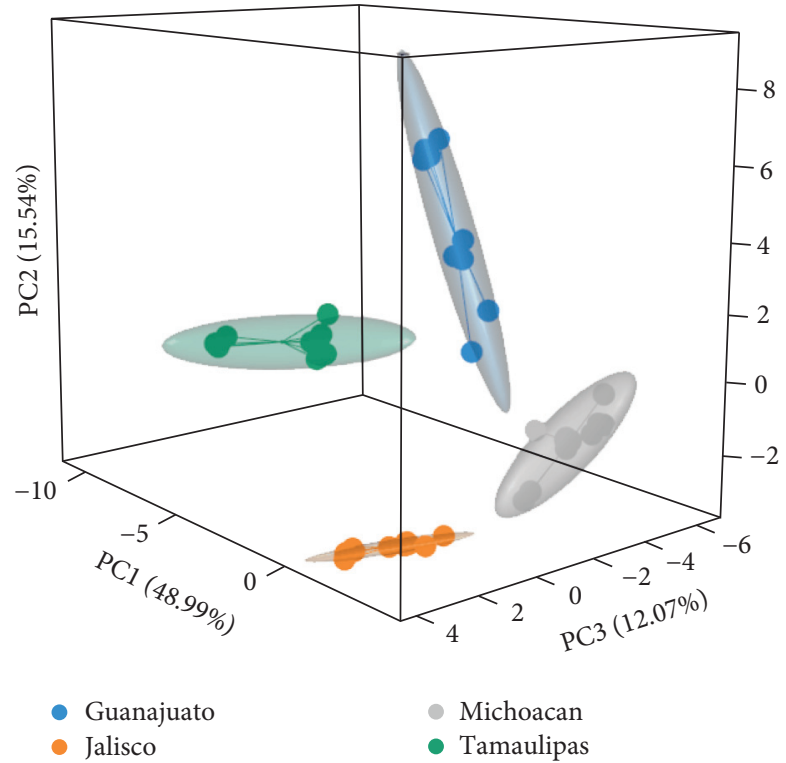

FIgUre 2: The three-dimensional figure of the PLS-DA model of identification of Mexican tequila.

TABLE 6: PLS-DA model validation of tequila from four regions of Mexico.

\begin{tabular}{lcccc}
\hline Geographical origin & Guanajuato & Jalisco & Michoacan & Tamaulipas \\
\hline Guanajuato & 4 & 0 & 0 & 0 \\
Jalisco & 0 & 3 & 0 & 0 \\
Michoacan & 1 & 0 & 0 & 0 \\
Tamaulipas & 0 & 100 & 100 & 5 \\
Prediction accuracy rate (\%) & 75 & 0 & 100 \\
\hline
\end{tabular}




\section{Conclusion}

After the data was measured by the stable carbon isotope $\delta^{13} \mathrm{C}$ of ethanol and the stable oxygen isotope $\delta^{18} \mathrm{O}$ of water in tequila, ICP-MS was applied to analyze the measurement results of 22 metal elements in tequila. On this base, the geographical origin model was constructed, the overall prediction accuracy of which reached $93.75 \%$. Therefore, the model is deemed reliable. In the future, it is still necessary to further increase the sample size and improve the accuracy of the follow-up model in geographical origin prediction.

\section{Data Availability}

The precision and accuracy of ICP-MS in determining 22 elements in tequila wine through standard recovery experiments are from ref. [18].

\section{Conflicts of Interest}

The authors declare that they have no conflicts of interest.

\section{Acknowledgments}

The research project was supported by the Research Project of Administration for Market Regulation of Guizhou Province, science and technology project supported by the General Administration of Quality Supervision, Inspection and Quarantine of the People's Republic of China (2015IK064), and Planning Research Project of Science and Technology of Guizhou Province (Qian KHZC [2017]2549).

\section{References}

[1] S. M. Rodrigues, M. Otero, A. A. Alves et al., "Elemental analysis for categorization of wines and authentication of their certified brand of origin," Journal of Food Composition \& Analysis, vol. 24, no. 4, pp. 548-562, 2011.

[2] I. Geana, A. Iordache, R. Ionete, A Marinescu, A Ranca, and M. Culea, "Geographical origin identification of Romanian wines by ICP-MS elemental analysis," Food Chemistry, vol. 138, no. 2, pp. 1125-1134, 2013.

[3] C. Bo, Y. Zhi, Z. Xu et al., "Regional discrimination of 10 kinds Chinese famous tea by multielement analysis," Natural Science Journal of Xiangtan University, vol. 38, no. 1, pp. 61-67, 2016.

[4] C. Bo, B. H. Jin, Y. Zhi et al., "Discrimination of 6 kinds of Chinese tea by combination of organic components and multielement analysis," Food Science, vol. 35, no. 18, pp. 119-123, 2014.

[5] M. Lei, T. Ke, H. Yehui et al., "Analysis of primary amino acid profiles of Italian Riesling white wines and their contribution to regional characteristics," Science and Technology of Food Industry, vol. 33, no. 19, pp. 128-133, 2012.

[6] X. Q. Fei, C. Y. Shen, W. Bin et al., "Detection of Royal Jelly adulteration using elemental analyzercarbon isotope ratio mass spectrometry," Journal of Chinese Mass Spectrometry Society, vol. 35, no. 2, pp. 144-148, 2014.

[7] H. Wu, L. Xie, B. Jin et al., "Gas chromatography-combustion isotope ratio mass spectrometry for the determination of five volatile components in wine and its application in geographical origin traceability," Chinese Journal of Analytical Chemistry, vol. 6, pp. 344-349, 2015.

[8] Y. Zhao, B. Zhang, B. Guo et al., "Combination of multielement and stable isotope analysis improved the traceability of chicken from four provinces of China," CyTA-Journal of Food, vol. 2, no. 1, pp. 1-6, 2015.

[9] W. Jiang, J. Xue, X. Liu, D.-l. Wang, Y. Guo, and L. Wang, "The application of SNIF-NMR and IRMS combined with C, $\mathrm{H}$ and $\mathrm{O}$ isotopes for detecting the geographical origin of Chinese wines," International Journal of Food Science \& Technology, vol. 50, no. 3, pp. 774-781, 2015.

[10] B. L. Guo, Y. M. Wei, J. R. Pan, and Y. Li, "Stable C and N isotope ratio analysis for regional geographical traceability of cattle in China," Food Chemistry, vol. 118, no. 4, pp. 915-920, 2010.

[11] Y. W. Yuan, Y. X. Zhang, H. Y. Fu et al., "Application of PCALDA method to determine the geographical origin of tea based on the determination of stable isotopes and multielements," Journal of Nuclear Agricultural Sciences, vol. 27, no. 1, pp. 47-55, 2013.

[12] T. S. Pilgrim, R. J. Watling, and K. Grice, "Application of trace element and stable isotope signatures to determine the provenance of tea (Camellia sinensis) samples," Food Chemistry, vol. 118, no. 4, pp. 921-926, 2010.

[13] M. R. Tan, H. Lin, C. Y. Shen et al., "Detection of fermented soy sauce adulteration using elemental analyzer carbon isotope ratio mass spectrometry," Journal of Chinese Mass Spectrometry Society, vol. 36, no. 4, pp. 334-340, 2015.

[14] D. Luo, H. Luo, H. Dong et al., "Hydrogen $(2 \mathrm{H} / 1 \mathrm{H})$ combined with carbon $(13 \mathrm{C} / 12 \mathrm{C})$ isotope ratio analysis to determine the adulteration of commercial honey," Food Analytical Methods, vol. 9, no. 1, pp. 1-8, 2016.

[15] S. Antje, C. Stefanie, S. Claus et al., "Multi-element stable isotope ratios $(\mathrm{H}, \mathrm{C}, \mathrm{N}, \mathrm{S})$ of honey from different European regions," Food Chemistry, vol. 121, no. 3, pp. 770-777, 2010.

[16] I. K. Karabagias, G. Casiello, S. Kontakos, A. P. Louppis, F. Longobardi, and M. G. Kontominas, "Investigating the impact of botanical origin and harvesting period on carbon stable isotope ratio values $(13 \mathrm{C} / 12 \mathrm{C})$ and different parameter analysis of Greek unifloral honeys: a chemometric approach for correct botanical discrimination," International Journal of Food Science \& Technology, vol. 51, no. 11, pp. 2460-2467, 2016.

[17] R. Fonseca-Aguiñaga, H. Gómez-Ruiz, F. Miguel-Cruz et al., "Analytical characterization of tequila (silver class) using stable isotope analyses of $\mathrm{C}, \mathrm{O}$ and atomic absorption as additional criteria to determine authenticity of beverage," Food Control, vol. 112, pp. 1-8, 2020.

[18] R. Fonseca-Aguiñaga, W. M. Warren-Vega, F. Miguel-Cruz et al., "Isotopic characterization of $100 \%$ agave tequila (silver, aged and extra-aged class) for its use as an additional parameter in the determination of the authenticity of the beverage maturation time," Molecules, vol. 26, no. 1719, pp. 1-11, 2021.

[19] L. Bontempo, R. Larcher, F. Camin et al., "Elemental and isotopic characterisation of typical Italian alpine cheeses," International Dairy Journal, vol. 21, no. 6, pp. 441-446, 2011.

[20] S. Z. Shao, Y.-L. Chen, Y. Z. Zhang et al., "Determination of the geographical origin of rice by PCA-LDA based on the stable isotopes and multielements concentrations," Journal of Nuclear Agricultural Sciences, vol. 29, no. 1, pp. 119-127, 2015.

[21] B. Worley, S. Halouska, and R. Powers, "Utilities for quantifying separation in PCA/PLS-DA scores plots," Analytical Biochemistry, vol. 433, no. 2, pp. 102-104, 2013. 
[22] D. Ballabio and V. Consonni, "Classification tools in chemistry. Part 1: linear models. PLS-DA," Analytical Methods, vol. 5, no. 16, pp. 3790-3798, 2013.

[23] J. Zhan, L. Tian, J. Yang et al., "Detection of 22 elements in tequila by inductively coupled plasma mass spectrometry," Liquor-Making Science \& Technology, vol. 8, pp. 121-123, 2016.

[24] J. Zhan, Y. Y. Lu, Z. Q. Tian et al., "ICP-MS detection of lead in food, arsenic,mercury, cadmium, barium, chromium, silver, nickel 8 harmful elements," The Food Industry, vol. 3, pp. 278-281, 2015.

[25] International Organization of Vine and Wine. Oenology resolutions., "detemination by isotope ratio mass spectometry $13 \mathrm{C} / 12 \mathrm{C}$ of wine enthanol or that obtained through the fermentation of musts, concentrated musts or grape sugar,". France resolution: international organization of vine and wine (OIV). Resolution OENO 17/2001.

[26] B. O. Aguilar-Cisneros, M. G. López, E. Richling, F. Heckel, and P. Schreier, "Tequila authenticity assessment by headspace SPME-HRGC-IRMS analysis of $13 \mathrm{C} / 12 \mathrm{C}$ and $18 \mathrm{O} / 16 \mathrm{O}$ ratios of ethanol," Journal of Agricultural and Food Chemistry, vol. 50, no. 26, pp. 7520-7523, 2002. 